\title{
Alcohol restrictions in Indigenous communities: an effective strategy if Indigenous-led
}

\author{
Dennis Gray \& Edward Wilkes
}

While it is encouraging to read Margolis and colleagues' findings in this issue of the Journal that in four Indigenous communities in Cape York, Queensland, there has been a marked reduction in aeromedical retrievals for serious injuries, the extent to which this is an indicator of a reduction in alcohol-related harm is uncertain. ${ }^{1}$

Robust measurement is crucial in identifying the most effective strategies to reduce alcohol-related harm. Development of aetiological fractions that enable us to measure, with a reasonable degree of accuracy, indicators such as alcohol-caused deaths and hospital admissions, has been a major step in this direction. ${ }^{2,3}$ However, rates of retrieval for all serious injuries are not among such indicators. No work has been undertaken to identify what proportion of such retrievals are actually alcohol-related, and the validity and reliability of retrieval rates as an indicator of alcohol-related harm have not been demonstrated. However, emergency department presentations provide a rough guide, with Australian research showing that between 22\% and 33\% of presentations are alcohol-related. ${ }^{4-6}$ Clearly, the higher levels of hazardous alcohol consumption in Indigenous communities and the different age-structures in the Indigenous and non- Indigenous populations complicate comparisons with data from metropolitan hospitals.

Although not available to Margolis et al at the time of writing, aetiological fractions have recently been developed for Australian emergency department presentations.7 In the absence of these, the authors could have obtained a more accurate picture of the impact of alcohol restrictions by using data on ICD-9 and ICD-10 diagnostic coding of injuries, applying hospital aetiological fractions to these, and adjusting the results for age.

Discussing their results, the authors state that "Focusing on supply reduction in the absence of demand-reduction strategies may lead to increasing use of other substances (eg, petrol sniffing or marijuana), as the fundamental issue of substance misuse has not been addressed." This raises two issues. First, there is a view that restricting the availability of alcohol is a stop-gap measure until other strategies are put in place. However, as levels of consumption are a function of both supply and demand, we contend that supply reduction itself (although not sufficient) is addressing the fundamental issue. ${ }^{8}$

The second issue has to do with substitution. The authors write that there were indications “. . . that some people who consumed alcohol had taken up cannabis use after the first [supply-reduction strategy], some for the first time.” This may be true and we certainly support calls for the provision of a wider range of demand-reduction 
strategies. However, there is not a simple one-to-one substitutability between drugs. ${ }^{9}$ Poly-drug use is common in the Indigenous population and, in the face of alcohol restrictions, some people will increase their use of cannabis or other drugs. ${ }^{10}$ Use of cannabis by Indigenous people, particularly in regional and remote areas, has been increasing - even in areas not subjected to alcohol restrictions. ${ }^{11}$ Taken together, and in the absence of hard data on the magnitude of any change in these communities, care needs to be exercised in attributing changes to restrictions per se - especially when such attributions may be used by opponents to undermine what has already been shown to be an effective harm-reduction strategy. ${ }^{12}$

That additional restrictions on alcohol supply have been shown to be effective raises the issue of whether they should be imposed on Indigenous communities. Our response to this is a resounding "No". For nearly 20 years, Indigenous community organisations, such as those in Tennant Creek and Alice Springs, have been at the forefront of advocating for and implementing additional restrictions on supply. Furthermore, before the Northern Territory Emergency Response (NTER), most remote NT communities had imposed their own bans on alcohol consumption. There is evidence to show that in towns such as Halls Creek and Fitzroy Crossing in Western Australia, where Aboriginal and non-Aboriginal leaders have worked together, restrictions on alcohol sales have benefited these towns significantly. ${ }^{13}$ Blanket bans such as those imposed on remote communities under the NTER are counterproductive. They take away Indigenous initiative, leading to resentment and exacerbation of existing social problems, both of which undermine willingness to work cooperatively with outsiders to address such problems. Indigenous Australians need support to control their own way out of poverty - including addressing harmful alcohol and other drug use, which are consequences of that poverty.

\section{Author details}

Dennis A Gray, MA, MPH, PhD, Professor, Medical Anthropology

Edward T Wilkes, BA, Associate Professor, Chair of the National Indigenous Drug and Alcohol Committee

National Drug Research Institute, Curtin University of Technology, Perth, WA.

Correspondence: D.Gray@curtin.edu.au

\section{References}

1 Margolis SA, Ypinazar VA, Muller R, Clough A. Increasing alcohol restrictions and rates of serious injury in four remote Australian Indigenous communities. Med J Aust 2011; 194: 503-506. 
2 English D, Holman C, Milne E, et al. The quantification of drug caused morbidity and mortality in Australia. Canberra: Commonwealth Department of Human Services and Health, 1995.

3 Ridolfo B. Stevenson C. The quantification of drug-caused mortality and morbidity in Australia, 1998. Canberra: Australian Institute of Health and Welfare, 2001. (AIHW Cat. No. PHE 29; Drug Statistics Series No. 7.)

4 McLeod R, Stockwell T, Stevens M, Phillips M. The relationship between alcohol consumption patterns and injury. Addiction 1999; 94: 1719-1734.

5 Poynton SN, Donnelly N, Weatherburn D, et al. The role of alcohol in injuries presenting to St Vincent's Hospital Emergency Department and the associated short-term costs. Alcohol Stud Bull 2005; (6).

6 Watt K, Purdie DM, Roche AM, McClure RJ. Risk of injury from acute alcohol consumption and the influence of confounders. Addiction 2004; 99: 1262-1273.

7 Chikritzhs T, Evans M, Gardner C, et al. Australian alcohol aetiologic fractions for injuries treated in emergency departments. Perth: National Drug Research Institute, Curtin University of Technology, 2011.

8 Ministerial Council on Drug Strategy. The National Drug Strategy 2010-2015. A framework for action on alcohol, tobacco, and other drugs. Canberra: Australian Government Department of Health and Ageing, 2011.

9 Saffer H, Chaloupka FJ. Demographic differentials in the demand for alcohol and illicit drugs. In: Chaloupka FJ, Grossman M, Bickel WK, Saffer H, editors. The economic analysis of substance use and abuse: an integration of econometric and behavioral economic research. Chicago: University of Chicago Press, 1999: 187-212.

10 Gray D, Stearne A, Wilson M, Doyle MF. Indigenous-specific alcohol and other drug interventions: continuities, changes and areas of greatest need. Canberra: Australian National Council on Drugs, 2010. (ANCD Research Paper 20.)

11 Gray D. The Northern Territory Emergency Response and cannabis use in remote Indigenous communities [letter]. Med J Aust 2010; 192: 555.

12 National Drug Research Institute (Chikritzhs T, Gray D, Lyons Z, Saggers S, contributors). Restrictions on the sale and supply of alcohol: evidence and outcomes. Perth: NDRI, Curtin University of Technology, 2007.

13 Kinnane S, Farringdon F, Henderson-Yates L, Parker H. Fitzroy Valley alcohol restriction report. An evaluation of the effects of alcohol restriction in Fitzroy Crossing relating to measurable health and social outcomes, community perceptions and alcohol related behaviours after two years. Perth: Drug and Alcohol Office, 2010. 